\title{
Determination of background concentrations of tropospheric ozone in natural and anthropogenically changed conditions using the phase portraits approach
}

\author{
Aleksandr Khaustov ${ }^{1, *}$, Margarita Redina ${ }^{1}$, Nonna Khaustova ${ }^{2}$ \\ ${ }^{1}$ Peoples Friendship University of Russia (RUDN University), Faculty of Ecology, 6 Miklukho- \\ Maklaya Street, Moscow, 117198, Russian Federation \\ ${ }^{2}$ Plekhanov Russian University of Economics, 117997 Stremyanny per. 36, Moscow, Russia
}

\begin{abstract}
. Н основе анализа суточной и месячной динамики получены фоновые значения, которые могут впоследствии использоваться для управления качеством атмосферы в рамках квотирования выбросов. Полученные оценки верифицировались с использованием официальных методических указаний. Показано, что методики дают близки значения фоновых концентрация для более длительных периодов наблюдений. Tropospheric ozone is one of the most active and toxic pollutants in the atmosphere. The dynamics of its concentrations is determined not only by the characteristics of emissions of precursor substances, but also by the complex of meteorological conditions. Atmospheric quality control requires the regulation of emissions based on the consideration of background concentrations and acceptable hygiene standards. The proposed article presents approaches to the estimation of background concentrations using the analysis of phase portraits based on continuous observations of the concentrations of ozone, its precursor substances, as well as a number of meteorological parameters. The dynamic phase portraits for the conditions of Moscow (Southern Administrative District) and the background territory (Krasnye polyany) are analyzed. Based on the analysis of daily and monthly dynamics, background values are obtained, which can later be used to control the quality of the atmosphere within the framework of emission quotas arrangement. The obtained estimates were verified using official methodological guidelines. It is shown that the methods give similar values of background concentrations for longer periods of observations (month and more).
\end{abstract}

\section{Introduction}

The problem of determining the background concentrations of pollutants in the surface layer of the atmosphere has been actively discussed for several decades. The practical need

\footnotetext{
* Corresponding author: khaustov-ap@,rudn.ru
} 
to establish these values appeared with the introduction of state methods for determining the dispersion of pollutants in the atmospheric air and regulating emissions. The background concentration is a reference point for determining permissible emissions: they are assigned as the maximum mass that allows you to "fill" the distance between the hygienic standard of the MPC and the actual background concentration. The need for calculations has become more acute due to a large-scale change in the rationing system in Russia and the introduction of emission quotas arrangement.

Close attention to ozone pollution of the surface layer of the atmosphere is caused by its extremely high chemical activity and toxicity to biota. Numerous studies have established the relationship of elevated ozone concentrations with the morbidity of the population (mainly cardiovascular and respiratory diseases). The peculiarity of ozone as a pollutant is its high reactivity and strong dependence on weather conditions, primarily the input of solar radiation. In this regard, ozone is an extremely interesting object for observation and modeling. The estimation of background ozone concentrations is a task of great scientific and practical importance.

\section{Research objects and methods}

The study is based on data from continuous monitoring stations for atmospheric air quality control located in anthropogenic-loaded and background areas [1]:

- in Moscow, Ordzhonikidze Street, 3 (Southern Administrative District of Moscow). Air samples are taken from a height of $5 \mathrm{~m}$; the post is protected by urban development from the direct influence of sources of ozone precursor substances (located in the courtyard of the RUDN University complex on Ordzhonikidze Street). There are no industrial sources of air pollution in the immediate vicinity of the post, the only industrial facility is CHPP-20 (gas-oil since 1994), but it is located at a distance of more than $2 \mathrm{~km}$,

- in the urban-type settlement of Krasnye Polyany in the Vyatskopolyansky district of the Kirov region of Russia (considered as a background station). Compared to Moscow, the atmosphere is certainly less affected by pollution.

The algorithm for determining background ozone concentrations, taking into account the description of the phase portrait method in $[2,3]$ in atmospheric air, is shown in Fig. 1.

Generating the initial data array for analysis

Selection of a data set for constructing a phase portrait based on the analysis of the increment of ozone concentrations over time.

The features of the analyzed data allow the use of robust statistics to identify differences between the characteristic levels of concentrations of the studied chemicals (the median as a single-point characteristic instead of the arithmetic mean and the interquartile range (an analog of the variance)

1. Analysis of zero concentrations of substances

2. Deleting extremely large sample data (less often, extremely small: replacing it with the minimum values of the lower limit of their detection).

3. Statistical evaluation of the distribution properties of sample data.

4. Estimation of the main trend of the time series based on the results of correlation analysis.

5. Selection of the mathematical function of the main trend of the time series, if available - spline

Determination of the background ozone concentration for the selected object at the selected time interval

Fig. 1. Algorithm for constructing a phase portrait of tropospheric ozone concentration 
As the initial data for determining the background concentration of ozone in the urban area (mainly the transport load with the entry of precursor substances into the atmosphere as part of the exhaust gases of vehicles with internal combustion engines), the results of measurements of the ozone concentration for the period from 0.00 hours of 1.11.2020 to 23.4030 .11 .2020 are taken. As a result of measurements with an interval of 20 minutes. data sets were obtained for both posts, containing 2160 records of concentrations of ozone, carbon monoxide, mono - and nitrogen dioxide, hydrocarbons, methane, and solid particles (total, PM 2.5, PM 4, PM10), temperature, humidity, wind speed and direction, atmospheric pressure and relative humidity, and precipitation intensity. The choice of the observation period (November) is due to the fact that this month is a transition between the winter and autumn periods. The input of solar radiation is one of the lowest during the year, which should affect the "saving" of ozone in the atmospheric air.

The samples were subjected to a correlation analysis; the parameters of the distribution of ozone concentrations and the basic statistical characteristics of the data set were also determined. To analyze the daily dynamics, we used cluster analysis procedures (Ward methods, Euclidean distances), which allowed us to determine the most typical days and then process the data for them, evaluating the daily dynamics of ozone and identifying background concentrations. All data analysis operations were performed using Statistica 10.

Verification of the obtained results was carried out using the approved state methodology for assessing the background concentrations of pollutants in the atmospheric air [4].

\section{Results and discussion}

\subsection{Estimation of background concentrations for Moscow conditions}

Previously, the complete sample was subjected to a correlation analysis; the parameters of the distribution of ozone concentrations and the basic statistical characteristics of the data set were also determined. almost all characteristics show relative independence: noticeable connections are revealed only in the groups of nitrogen oxides and dust. In the case of ozone, correlations of moderate significance were found with $\mathrm{CO}(+0.50)$ and wind speed $(+0.58)$. Thus, ozone concentrations in the surface layer of the atmosphere $(5 \mathrm{~m}$ above ground level) can be considered as relatively independent characteristics (or relations with other parameters have a form other than linear).

As one of the leading factors determining the dynamics of tropospheric ozone, the intensity of solar radiation is traditionally indicated. However, for the data considered above, such a relationship could not be established: the correlation coefficient is positive, but beyond the limits of significance: $r=0.27$.

An analysis of the monthly course of ozone concentrations showed that the distribution of concentrations differs from the normal one. A spline function was constructed to estimate the phase portrait of the $\mathrm{O}_{3}$ concentration for $01.11-30.11 .2020$. A 95\% confidence interval is selected. In this case, some of the points go beyond the ellipse of the $95 \%$ confidence interval. According to the methodology, these points should be removed from consideration, but it is also not possible to interpret this scheme. In this regard, further assessment of the background concentrations of the data for the month was carried out on the basis of averaged indicators (medians).

The assessment of the dynamics of the concentrations of a complex of pollutants (including ozone) and meteorological parameters based on the median values allowed us to establish significant negative correlations of the $\mathrm{O}_{3}$ concentration with the concentrations of $\mathrm{CO}$, NO, dust particles of all sizes, the humidity of the external environment, and a 
significant positive relationship with wind speed. Such correlation values can be explained by the consumption of $\mathrm{O}_{3}$ (a decrease in concentration) during the oxidation of the above compounds, or compounds sorbed on dust particles and aerosols (at high humidity). The positive relationship with wind speed can be explained by an increase in the exchange of air composition and the introduction of new portions of $\mathrm{O}_{3}$ or its precursors.

The construction of a dynamic phase portrait (Fig. 2) based on the median values allowed us to conditionally assume a background concentration of $0.014 \mathrm{mg} / \mathrm{m}^{3}$.

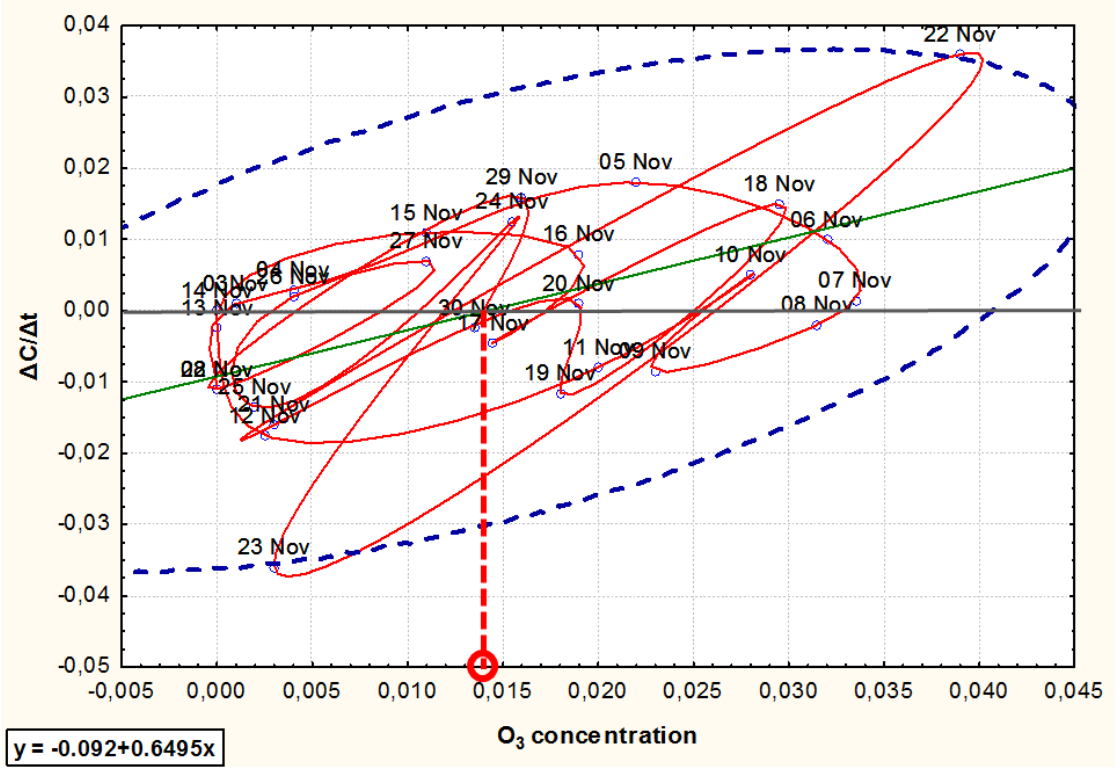

Figure 2. Dynamic phase portrait of ozone concentration based on median values for urban areas

To justify the "typical" days and estimate the daily course of $\mathrm{O} 3$ concentrations, the cluster analysis procedure was used. According to the results of the cluster analysis, the closest ones were 30.11 and 25.11 , to which the combining algorithm later allowed us to attach the remaining days of the month as the degree of similarity (Euclidean distance) decreases to the "central" dates. As a result, 30.11.2020 is accepted as the most typical day. In addition to the results of cluster analysis, these days are of greater interest due to the fact that 30.11 accounts for the minimum solar radiation according to NASA.

During the selected typical days, there are clear periods of maximum concentration, a period of sharp drop and a period of relatively stable fluctuations of $\mathrm{O}_{3}$ (Fig. 3). Note that this dynamics differs from the time variations of ozone established for a number of other regions of Russia (Transbaikalia, Tomsk region), as well as from the average estimates obtained earlier for the conditions of the autumn period for Moscow [5]: the maximum concentrations are reached at night. This can be explained both by the specifics of weather conditions and by the features of the daily dynamics of precursor substances. Their main sources are technogenic emissions (transport), with their characteristic dynamics of receipt and accumulation in the surface layer during the day. 


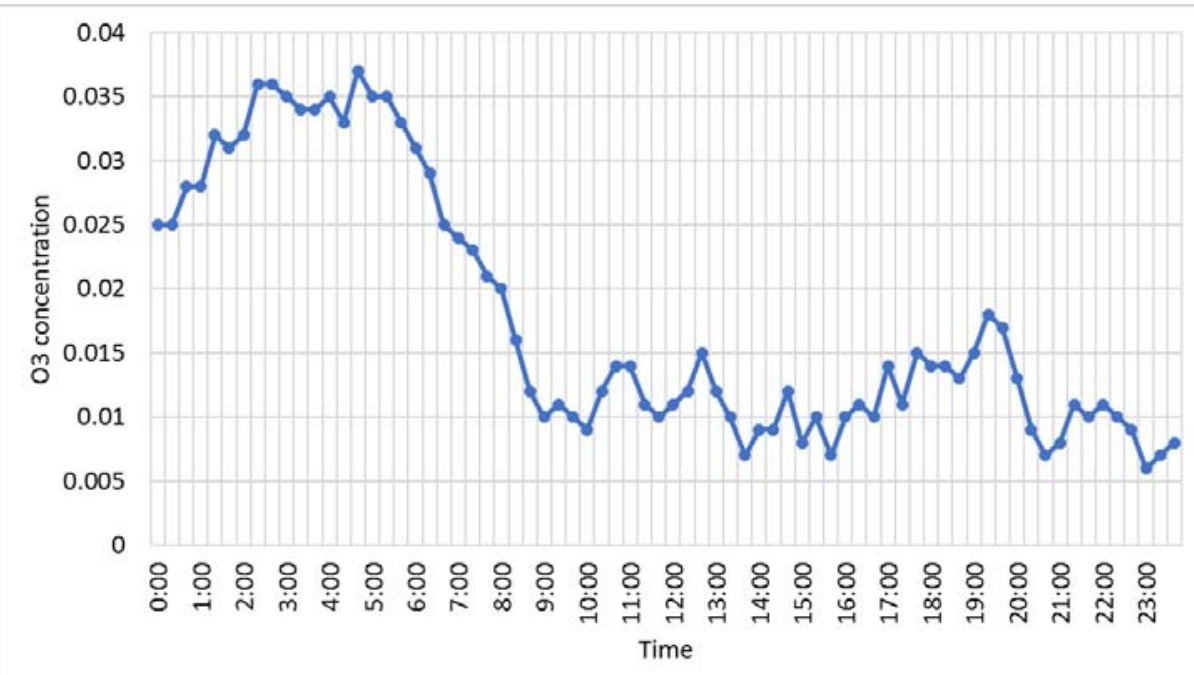

Fig. 3. Daily dynamics of O3 concentration during the "typical day" (30.11.2020) for Moscow conditions

After averaging the data (obtaining arithmetic averages for each of the 24 hours), the phase portrait of ozone concentrations takes the form (Fig. 4):

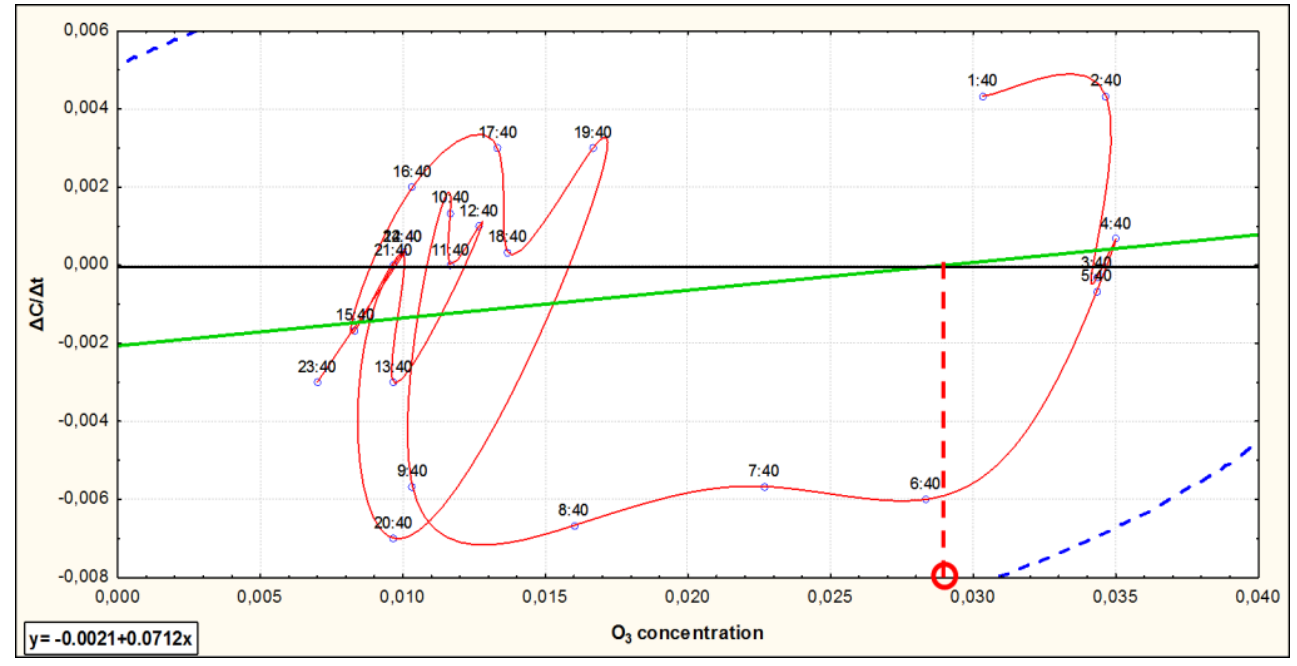

Fig. 4. Phase portrait of $\mathrm{O} 3$ concentrations based on averaging 72 measured values for 30.11 .2020 to 24 hourly averages for Moscow conditions

Thus, we can distinguish 2 areas of attractors: the extensive "day-evening" with low concentrations (from 8.40 to 23.40 ) and the early morning (2.40-5.40) with relatively higher concentrations of ozone in the surface layer of the atmosphere. The linear regression line crosses the abscissa axis at an $\mathrm{O}_{3}$ concentration of $0.029 \mathrm{mg} / \mathrm{m}^{3}$. As a result, for a "typical day" of 30.11.2020, a background ozone concentration of $0.029 \mathrm{mg} / \mathrm{m}^{3}$ can be estimated. Note that this value is not "background" in the sense of matching the natural background. This concentration can be more accurately called the typical daily concentration for the selected observation point. This value, of course, is determined by a complex of natural (meteorological parameters, properties of ozone, its precursors and 
decay products) and anthropogenic (the totality of emissions from sources in the zone of influence of which the control point is located).

\subsection{Dynamics of tropospheric ozone in the background area}

The assessment of correlations of ozone concentrations with other controlled parameters shows the presence of a negative relationship of the average strength between the concentration of ozone and $\mathrm{CO}$ and a positive one - with the wind speed.

When assessing the dynamics of ozone concentrations using a complete data set, sharp changes in $\mathrm{O}_{3}$ concentrations are identified during the day. However, in general, the average concentrations for the month, judging by the regression line, do not experience significant changes and the limits of concentration changes remain at a level not higher than $0.05 \mathrm{mg} / \mathrm{m}^{3}$.

Then the median values for 30 days of observations (30 medians) were obtained. Correlation analysis of this array showed that for ozone concentrations there are significant and strong relationships with $\mathrm{CO}, \mathrm{NO}$, dust particles, wind speed, and ambient humidity. These connections can be explained as follows.

$\mathrm{CO}$ and NO are oxidizable compounds, so their inverse correlation with the concentration of ozone as a powerful oxidant is quite understandable. The same applies to the relationship with dust particle concentrations: ozone can be used for the oxidation of compounds sorbed on dust particles and aerosols. Also, the negative connection of ozone could be explained by a decrease in the amount of solar radiation entering the earth's surface due to the dustiness of the atmosphere. Note that there are no obvious links between the level of solar radiation coming to the Earth's surface and any of the other measured parameters. It is possible that these relationships can be detected by taking into account the delayed effect, but more research is needed for such estimates. The phase portrait of ozone concentrations based on the median values for the month is shown in Fig.5.

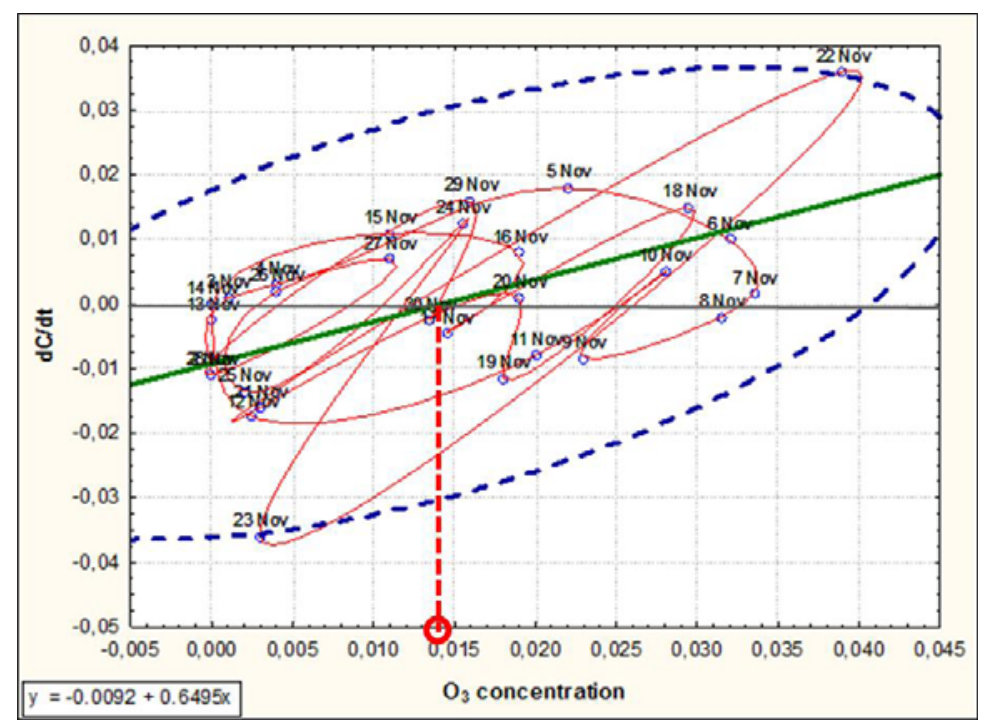

Fig. 5. Phase portrait of ozone concentrations by median values for 1-30.11.2020 for the background area

As can be seen from the graph, 2 obvious attractor regions are not formed. The typical concentration can be assumed to be $0.14 \mathrm{mg} / \mathrm{m}^{3}$.

As a representative day according to the scheme given above, 30.11.2020 is selected. 
Note that the nature of daily variations in $\mathrm{O} 3$ concentrations here is similar to the Moscow conditions (Fig. 6).

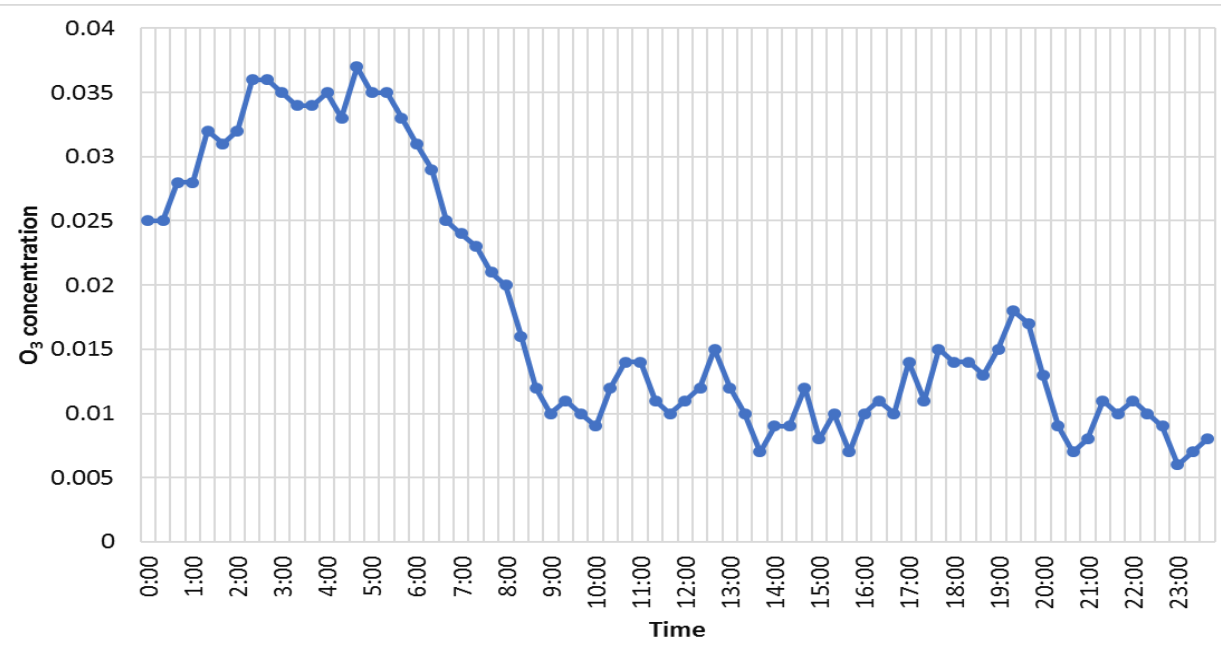

Fig. 6. Daily dynamics of O3 concentrations during the "typical day" (30.11.2020) for the background territory

The dynamic phase portrait of $\mathrm{O}_{3}$ concentrations in Krasnye polyany settlement for the typical day November $30^{\text {th }}$ is shown in (Fig. 7).

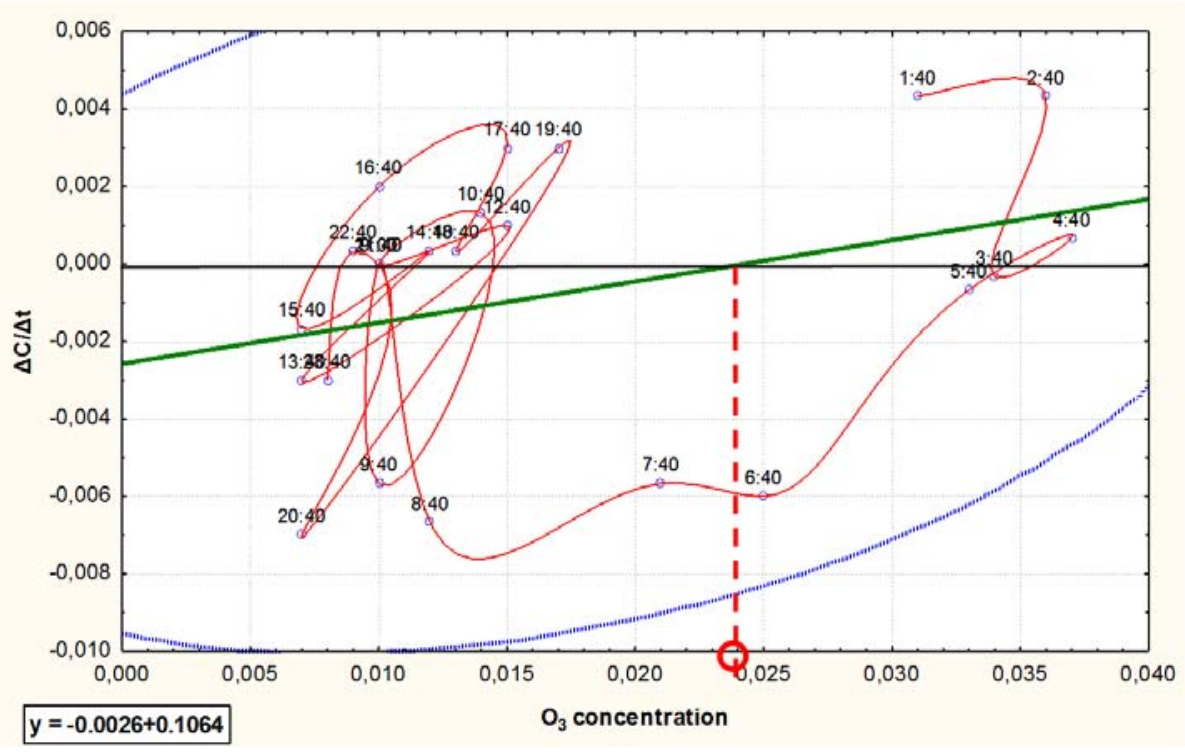

Fig. 7. Dynamic phase portrait of $\mathrm{O} 3$ concentrations in the background area by averaged hourly concentrations for a representative day

The figure clearly shows the area of the attractor corresponding to the period of the day from 8.40 to 23.40. It also shows the formation of the yet another one area of the attractor in the early night and morning hours (from $1 \mathrm{~h} 40 \mathrm{~min}$ and further). The value of the background (typical) ozone concentration according to the data for the representative day corresponds to $0.024 \mathrm{mg} / \mathrm{m}^{3}$. 


\subsection{Verification of background concentrations}

Verification of the obtained values of background concentrations based on the data set for the month and on the results of averaging for the day was carried out by comparing them with the results of calculations according to officially approved methodological recommendations [4]. They implement a different estimation algorithm (data averaging) and contain a number of requirements for the formation of an array (in particular, significant amounts of data). The results of comparing the values of the background concentrations, as well as the established values of the MPC, are shown in Table 1.

Table 1. Comparison of MPC and $\mathrm{C}_{\text {bakgr }}$ of ozone according to data for a month and for a typical day for the conditions of Moscow and the background territory, $\mathrm{mg} / \mathrm{m}^{3}$

\begin{tabular}{|c|c|c|c|c|c|c|c|}
\hline \multirow[t]{2}{*}{ Ares } & \multicolumn{2}{|c|}{$\begin{array}{l}\text { C }_{\text {bakgr }} \text { for the month } \\
\text { period }\end{array}$} & \multicolumn{2}{|c|}{$\begin{array}{c}\text { C bakgr at representative } \\
\text { day Nov. 30 }\end{array}$} & $\begin{array}{l}\text { MPC } \\
\text { daily }\end{array}$ & $\begin{array}{l}\text { MPC } \\
\text { maximum }\end{array}$ & $\begin{array}{l}\text { MPC } \\
\text { for the }\end{array}$ \\
\hline & $\begin{array}{c}\text { Using } \\
\text { phase } \\
\text { portrait }\end{array}$ & $\begin{array}{l}\text { According } \\
\text { to the } \\
\text { Guideline }\end{array}$ & $\begin{array}{c}\text { Using } \\
\text { phase } \\
\text { portrait }\end{array}$ & $\begin{array}{c}\text { According } \\
\text { to the } \\
\text { Guideline }\end{array}$ & \multirow{3}{*}{0.030} & \multirow{3}{*}{0.160} & \multirow{3}{*}{0.100} \\
\hline Moscow & 0.014 & 0.016 & 0.029 & 0.018 & & & \\
\hline $\begin{array}{l}\text { Krasnye } \\
\text { polyany }\end{array}$ & 0.014 & 0.015 & 0.024 & 0.012 & & & \\
\hline
\end{tabular}

The data in the table show a good agreement between the background concentrations estimated by the method of dynamic phase portraits and the official method on the monthly data sets. However, in the case of estimates of background concentrations based on daily data, there are significant differences (1.5-2 times). This may be explained by the averaging method: in the case of the phase portrait method, the median values are used (which are then further averaged for hourly time intervals), and in the case of the official method, the background concentration is added up as a weighted average, taking into account the arithmetic mean ozone concentrations per day and the proportion of time when there were winds of less than $2 \mathrm{~m} / \mathrm{s}$, and (at a speed of more than $2 \mathrm{~m} / \mathrm{s}$ ) - by 4 points.

Note that the obtained values do not exceed in any of the cases the most stringent MPC standard (average daily), although the value for representative days in Moscow is very close to the critical one.

\section{Conclusion}

The analysis of the dynamics of the concentration of tropospheric ozone in the background and anthropogenic areas for November 2020 allows us to draw the following conclusions.

1. During the day, both in the conditions of the background territory and in the conditions of anthropogenic loads (mainly transport emissions), there are clear maxima of concentrations in the morning hours. Interestingly, a number of studies show morning lows [6-8]. A possible explanation is the specific nature of the solar radiation input in the European and Asian territories.

2. No dependence of $\mathrm{O}_{3}$ concentrations on the arrival of solar radiation on the Earth's surface was found for either the background or the anthropogenic-loaded territory. It may be necessary to evaluate the delayed effects (the later reaction of the $\mathrm{O}_{3}$ concentration to the dynamics of solar radiation).

3. The relationship between the characteristics of the state of the surface layer of the atmosphere and the ozone concentration is established only by the median values of these parameters obtained for the daily period for 30 days from 1 to 30.11 .2020 (estimates for the background area). The identified negative relationships can be explained by the fact that 
ozone is consumed for the oxidation of the corresponding compounds (NO, CO, substances sorbed on dust particles). The negative relationship with air humidity can also be explained either by the oxidation of substances transported by aerosols (water particles), or by a decrease in the arrival of solar radiation in conditions of high humidity. The positive relationship with wind speed can be explained by a more active exchange and the introduction of new portions of ozone or oxygen from unpolluted areas.

Comparison of the results with the official guidelines showed a fairly good convergence of the results for longer observation periods (month). However, for the daily period, the values differ very significantly (1.5-2 times).

\section{References}

1. V.V. Andreev, M.Yu. Arshinov, B.D. Belan, D.K. Davydov, N.F. Elansky, G.S. Zhamsueva, A.S. Zayakhanov, G.A. Ivlev, A.V. Kozlov, S.N. Kotel'nikov, I.N. Kuznetsova, V.A. Lapchenko, E.A. Lezina, O.V. Postylyakov, D.E. Savkin, I.A. Senik, E.V. Stepanov, G.N. Tolmachev, A.V. Fofonov, I.V. Chelibanov, V.P. Chelibanov, V.V. Shirotov. Surface ozone concentration over the Russian territory in the first half of 2020. Optica atmosfery i okeana, 33(9), 710-721 (2020)

2. Trofimchuk M. M. Meteorologiya i gidrologiya, 7, 80-86 (2018)

3. N.V. Nikerina, O.V. Zadonskaya. The Fourth Vinogradov readings. Hydrology from cognition to worldview, 973-978 (2020).

4. Guidelines for determining the background level of atmospheric air pollution. Approved by the order of the Ministry of Natural Resources of the Russian Federation of 22.11.2019 N 794 .

5. N.F. Elansky, M.A. Lokoshchenko, A.V. Trifonova, I. B. Belikov, A.I. Skorokhod, Atmospheric and ocean physics, 51(1), P. 39-39 (2015)

6. M.Yu. Arshinov, B.D. Belan, D.K. Davydov, D.E. Savkin, T.K. Sklyadneva, G.N. Tolmachev, A.V. Fofonov, Trudy IOFAN, 71, 106-117 (2015)

7. M.E. Héroux, M. Braubach, N. Korol, M. Krzyzanowski, E. Paunovic, I. Zastenskaya, Gigiena i sanitariya, 6, 9-14 (2013).

8. G.S. Zhamsueva, A.S. Zayakhanov, V.V. Tsydypov, T.S. Balzhanov, D. Azzayaa, D. Oyunchimeg, Bull. of the Buryat Scientific Center of the Siberian Branch of the Russian Academy of Sciences, 2, 229-246 (2013) 